\title{
The Poetic and the Thoughtful: The Creative Poiesis of Algorithmic Art and Design
}

\author{
Iris Asaf \\ University College London \\ Gower St, London WC1E 6BT, U.K. \\ i.asaf@ucl.ac.uk, irisasaf@gmail.com
}

\begin{abstract}
Free subjective choices and selections form an inevitable part of the practice of algorithmic based design and art works. Notably, this aspect of decisions made by practitioners has featured in generative art and design literature, yet, has remained obscure and has not been critically discussed. In this paper I will examine artists' and designers' selections through three case studies representing different typologies of decision processes. The philosophical aspect of these decisions will be elaborated following Wittgenstein's paradox and the critical argument made by philosophers Jacques Bouveresse and Charles Taylor in that no rule, no matter how explicit and unambivalent can ever really determine its own application. The actual implementation of rule systems, therefore, is a practice in itself, one that entails finely tuned interpretations, as well as arbitrary and intuitive choices.
\end{abstract}

Finally, I will argue that this relates to what Heidegger later observed to be the original meaning of creative making, referring to the Greek word 'Poiesis', where the thoughtful aspect of the work and the poetic one are united in a non-separated praxis. Similar to the practice made by oulipo poets who use rule systems to enhance the creative engine of their work, I will argue that these decisions can potentially transform the practice of generative art and design to that of Poiesis in its original meaning: the free play and improvised confrontations with ever renewed unfolding situations, that eventually can lead to liberation from the rules themselves.

Generative art. Selection. Poiesis. Creativity.

\section{INTRODUCTION}

Practitioners of digital design find themselves often enough confronted with a unique aspect of an algorithmic - based work: the necessity to make selections and choices as well as to interpret the outcomes of the processes leading to ongoing transformative changes of the algorithmic systems. At times these decisions are perceived to be random-like, arbitrary or to simply stem from individual unique tastes without clear or explainable reasons. "Some experience, intuition, or creativity whatever you prefer - flows into this choice", admits algorithmic art pioneer, Frieder Nake (2012, 71). Similarly, Harold Cohen (2008) has described his difficulty in choosing among the many of AARON's outcomes.

Indeed, how to explain arbitrary and highly subjective choices within well-structured processes that rely heavily on coherent machine logic and mathematical principles?

In the following discussion I will critically examine this question by addressing the works: The
Serpentine Pavilion (2002) by Cecil Balmond and Toyo Ito, Random Polygon by Frieder Nake (1965) and the art work Niche Constructions by Jon McCormack (2010). In the next part of the paper I will further develop the question following Wittgenstein's critical approach as discussed by contemporary philosophers Jacques Bouveresse (1999) and Charles Taylor (1995), as well as the later phenomenology of Martin Heidegger. In the final part of the discussion I will also address the question of creativity in this context.

\section{SELECTION AND CHOICES AS TYPOLOGIES}

In the following section I offer an examination of three different types of selections, through the case studies, presenting three different applications of generative systems.

\subsection{The typology of rule selection: the Serpentine Gallery 2002, London, Toyo Ito and Cecil Balmond}

To begin, at the basic level of selection processes is the choice of the rules themselves. The 
Serpentine Gallery was built in the summer of 2002 in Hyde Park, London, by architect, Toyo Ito, with engineer Cecil Balmond and Arup (Figures 1-2).

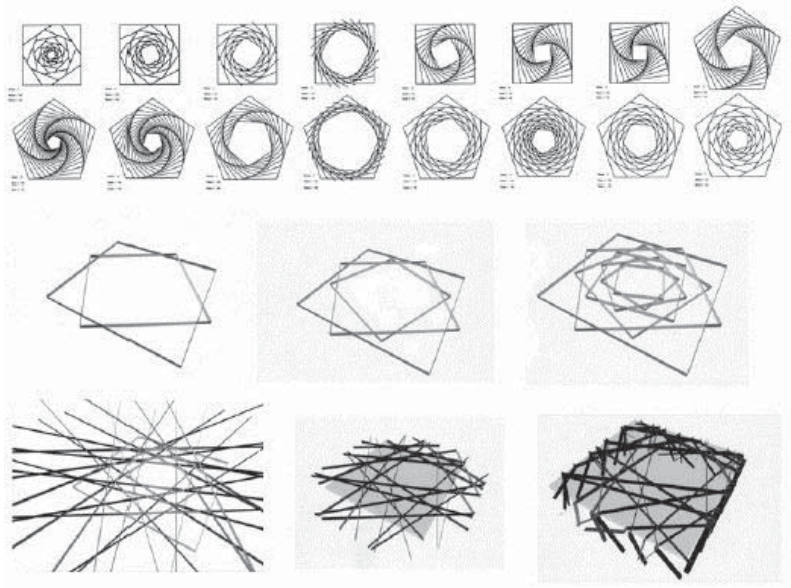

Figure 1: Explorations of Several Algorithmic Iterations: Cecil Balmond with Toyo Ito, The Serpentine Gallery Pavilion, 2002, London. Image Source: Arup AGU

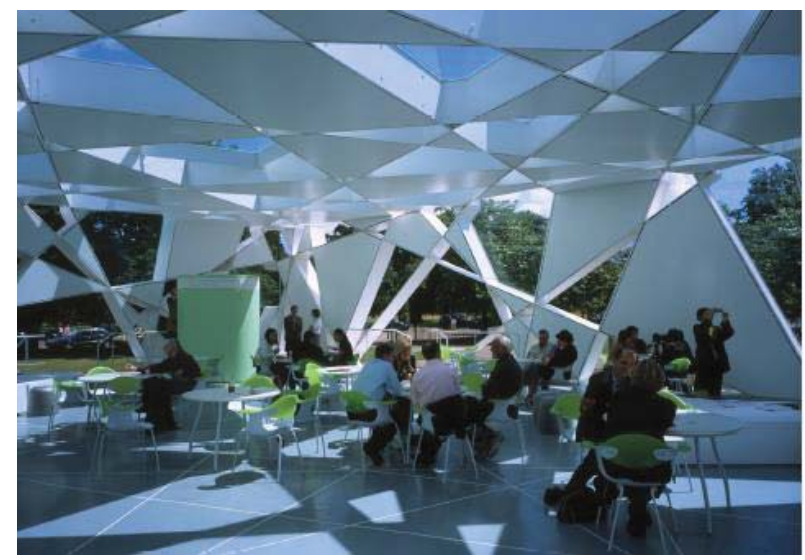

Figure 2: Cecil Balmond with Toyo Ito, The Serpentine Gallery, London, 2002. Image: ARUP AGU

Preliminary sketches during the first meetings between Ito and Balmond show an initial idea of a slab as an open enclosure of the pavilion, with a sketch by Ito of random like lines on the roof of a cube. This initial idea was selected as the main concept, for which a decision needed to be made as to how the lines would create a random pattern dividing the box.

After various unsatisfactory tryouts of hand sketches, Balmond and his team began exploring ways to generate the pattern through an algorithmic based process. Arup's sketches from these times show experiments with various geometric rules applied on a cube (Figure 1), but the final decision of the geometric rule was an intuitive one, as Balmond mentioned in an interview I conducted with him: "I thought of the billiard ball that bounces around, and if you go to (from) the half point to the half, it comes back to where you start. So, I started thinking, what happens if it doesn't come to the half? Where does the ball go? ... I realized you have to go out of the original square to make the new square... instinctively I knew this would work, how it would be, I didn't know". Following this decision, a dividing rule of a half to a third was selected and applied repeatedly; lines were extended to create the squares within, a cycle that continued six times until the initial structure was obtained.

Reasonably, letting the algorithm run for more cycles could have resulted in a more complex pattern. Nonetheless, a decision to stop after a certain amount of times had to be made. When I asked Balmond why he stopped running the algorithm at that certain point and not another, his answer was: "there is no point to stop. You just stop". Not giving up I asked him again and he answered that it did not matter, aside of the reason that a more complex pattern would have made a more difficult structure to construct. It is interesting to see that the designers here do not appear to have an explanation, yet, nor in their view, is an explanation needed.

In summary, Balmond and Ito's Pavilion introduces a typology of the first level, where the decision on the rule system itself forms the main aspect of choice and selection. Yet, running the algorithm in this case only provides a geometrical pattern, which is not yet a structure. For the pattern to have some architectural meaning both as a function and as a spatial structure, a re-interpretation of the pattern needed to be introduced. Balmond took the geometric web of lines given by the algorithm as a structural pattern, in which the lines formed steel beams linked to each other. Particular traces were made thicker for additional support, and in-between areas were used for triangular panelising of either steel or glass. As described by the designers themselves, it was one interpretation nested within the other (Ito \& Balmond 2002).

\subsection{The typology of intuitive-arbitrary selection: Frieder Nake's Random Polygon, 1965}

On top of the first level it is possible to add a typology of the second level with one of the very first experiments in computer art. The early pioneering work of mathematician and artist Frieder Nake, Random Polygon, is a mechanically made drawing of a single black line at horizontal, vertical and diagonal angels initially exhibited in Stuttgart, Germany in 1965 (Figure 3).

As described by the artist, the plotting machines at the time were only capable of producing straight lines segments, thus challenging the ability to create an aesthetic variety. The use of an 
algorithmic based process programmed in a machine-based language enabled to achieve some graphic complexity. The algorithmic principle for the drawing of a random polygon can read like this: choose an $x$ and a y coordinates, read given inputs and apply distribution function $F(x)$ and $F(y)$, draw a line from one point to the new point, make the last coordinates the beginning point of the next iteration, repeat until a given number of points (Nake 2012).

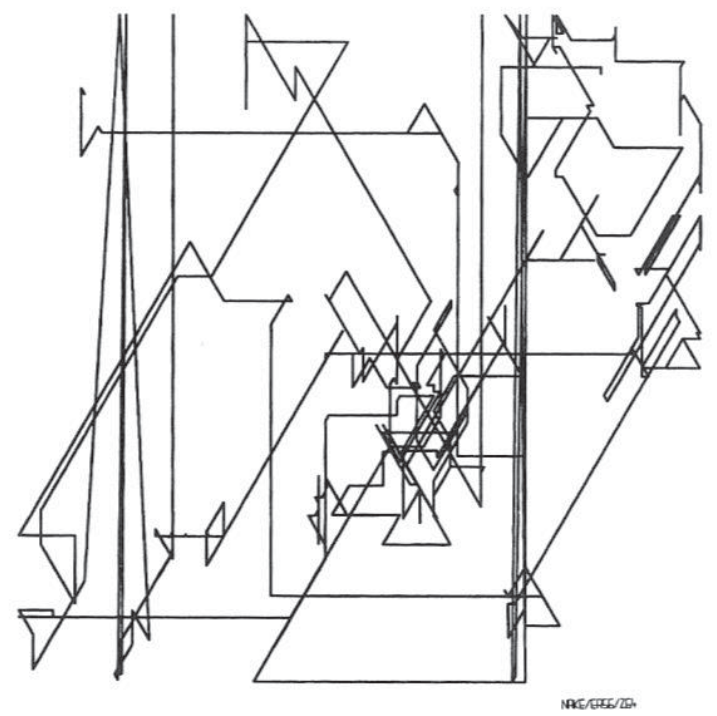

Figure 3: Frieder Nake: Random Polygon, 1965. Image: Nake $(2012,69)$

In this case, in addition to the first typology of rule selection previously described, exists a typology of arbitrary selection on different levels. Before each execution of the algorithm the artist had to select, arbitrarily, intuitively, on the spur of a moment, or following the results of previous outputs, a few variables: the first point to begin, the total number of points, the size of the drawing area and the stroke weight of the mechanical pencil. These selections would determine in part, the direction of the application of the algorithm. To that, another selection is added, the pseudo random distribution, determining the next point and the next line of the drawing. Because of the stochastic-based selection, an execution of the algorithm with the same chosen inputs would produce different imagery. Thus, Nake's algorithm is capable of producing an infinite number of different polygons adapted to an infinite number of possible inputs. The random based procedure limits what the machine eventually will formulate, yet, Nake still needed to make his own selection among the many to display in the exhibition. The artist made many trials before selecting this one. This particular composition became later well known and perhaps it represents the ensemble of random polygons drawn by the ER56 machine well enough. Perhaps this image best appealed to the artist's sense of aesthetics. For which ever reason, there is no valid explanation for that particular one over the others, other than the reason that Nake chose that one.

\subsection{The typology of embedded selection: Jon McCormack's Niche Constructions, 2010}

The designer and computer scientist, Jon McCormack's work is by large based on the concept of an ecosystem and its metaphorical translation to a community of interlinked components interacting within a simulated environment and forming mutual relations of influence through evolution and adaptation. Evolutionary computational approaches are often applied as the generative mechanisms.

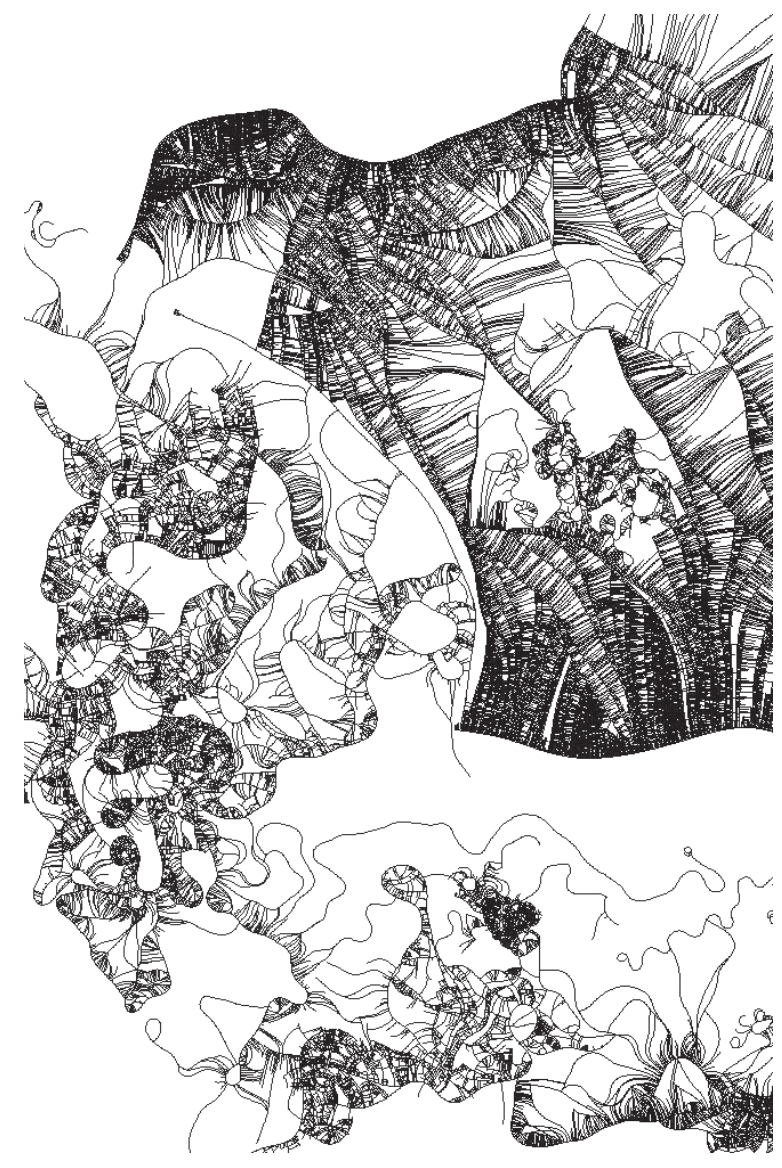

Figure 4: Jon McCormack (2010), Niche Constructions. A detail of a sample output from the line drawing system. Image source: http://jonmccormack.info

The art work Niche Constructions (Figure 4) is based on agents drawing lines on an initial white canvas. Each agent is set with genetic properties which direct its evolving behaviour over time, such as the curvature of the line drawing (Figure 5), and the agent's life span, which decreases as line density increases. Although no limit is applied to the number of offsprings, eventually the entire population dies, since intersections and running off page situations are defined as causes of agents dying off. When the entire population dies, the image is finished. Another mechanism ('self- 
observation') links an agent's line density with its state within the environment (fitness criteria such as its ability to survive and reproduce). This results in variable drawing behaviours: from large low density closed spaces to dense areas (McCormack 2012).

At the level of the first typology, the system's model includes various properties and their features that are pre-given by the designer, such as the properties of the components and their environment, inclusionary, exclusionary and casual rules that adjust a component's behaviour and its interaction with the environment, as well the overall feedback and regulation mechanism of the system. During the construction of the model the programmer interacts with all kinds of unexpected or strange behaviours that emerge and require reprogramming. However, beyond this level of selection, what is added is an internal mechanism of embedded selection. The system is programmed to encourage variety through its self regulating mechanism during which drawing behaviours are transformed and adapted, until the process eventually stops, taking on the decision of when a drawing is done. Consequently, at least part of what was previously discussed as intuitive-arbitrary selection performed by an artist in order to limit the infinite range of outcomes by the generative system and to select an image, is regulated internally.
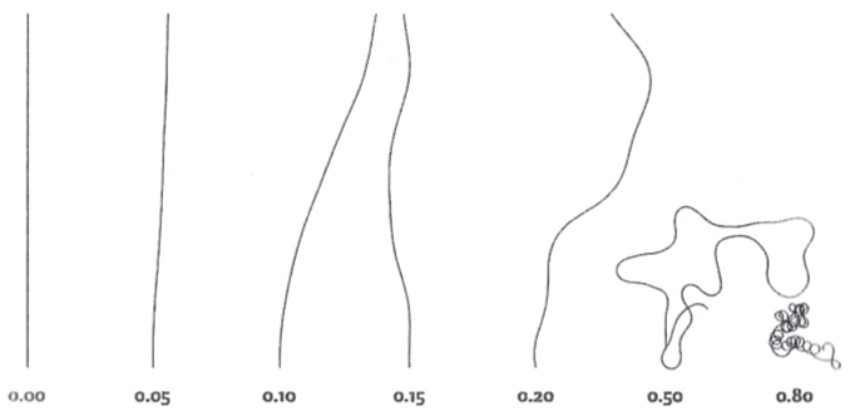

Figure 5: Individual drawing agents and their different 'genetic' value of curvature. Image: McCormack (2012, 55)

The three typologies discussed through the cases exemplify different processes of selection, yet one aspect is common to all. Regardless of the different ways in which the generative systems are structured, there are still reasonably large margins of indeterminacy and ambivalence as to their way of implementation that call for interpretations. This happens despite the impression often given by generative systems as explicit mechanisms that determine their own application. Generative design and art as a practice that automates and computerizes aspects that relate to the human agency, is thus faced with an inevitable 'leftover' of that agency, since someone still needs to set the rules and constrains or decide how many times the algorithm will run.

\section{RULES AS A PRACTICE}

Here begins the next part of this discussion, following what is known as Wittgenstein's 'skeptical paradox' in that no rule, no matter how explicit and non ambivalent, can ever really determine its own application. Philosophers Jacques Bouveresse (1999) and Charles Taylor (1995) relate to this paradox as part of Wittgenstein's analysis of the essential nature of following rules. And the essential nature of following rules is not representational or mechanical, although rules are systems of representation. The act of following rules is in itself a practice, and as such, its locus lies within the unformulated practical engagement with the world. As a practice it gives the rules their concrete shape in particular situations, interpreting and re-interpreting what they mean. For generative art and design this simply means that there is an underlying gap between what the rules say, and what their actual application in reality will be. Artists and designers are not, and cannot be aware of the whole set of issues concerning the implementation of the rules that they themselves construct.

One of Wittgenstein's examples is the case of following directions, that although are remarkably clear, can still be misunderstood. For instance, assuming I am new to London and it is my very first trip on the tube. I am trying to follow the TFL's tube map in order to get from Bakerloo station to Archway, so that I could meet someone, a Londoner, who said he would be waiting for me just a few steps up from Archway station near Whittington's cat. There is no question that the tube map is clear enough, and that all the instructions are there. In reality, however, there is a good chance I might overlook the sign of the Northern line, or, that I might end up on its wrong direction, or, that due to engineering works that day I will need to make a whole detour down the underground. Even if I did manage to get out of the correct tube station, I could still walk by the little bronze cat on the sidewalk, because I was looking at an actual cat near a pub called 'The Whittington'.

Understanding, in Taylor words, is "always against a background of what is taken for granted or just relied on" (Taylor1995, 167). Wittgenstein stresses the implicit, the unformulated, which in its essential nature is not representational. Accordingly, when artists and designers make decisions and selections without coherent reasons, it is the unarticulated that comes forth. They are, in fact, obliged to express it, as the unarticulated would never have emerged if it hadn't been for the practice of rules. 
This is precisely what happens when a mechanism, in the form of a generative system, directs an action whose locus lies in the non mechanical world. A generative system, no matter how autonomous, still does not apply itself. It has to be applied, whether through reciprocal exchanges of programming and re-programming that artificial life practitioners such as Jon McCormack do, or through arbitrary and intuitive selections of variables and outputs as in Freider Nake's early processes, or through explicitly constructing rules and re-interpreting them in specific contexts, as in Toyo Ito and Cecil Balmond's case. In whichever method generative designers and artists construct their work, they still make finely tuned judgments and inarticulate interpretations however arbitrary.

It is remarkable but not surprising to find designers and artists at a loss over what might seem a paradoxical situation. Practitioners, on one hand, direct highly structured processes that rely on regularities and embed logical, scientific principles; and on the other, are faced with unpredictable outcomes which they cannot explain, and take decisions for inexplicable reasons that mainly rely on brute causality. On the surface it seems that if we only understood the mechanisms better, we would be able to explain both the outcomes and the decisions.

This paradox for Bouveresse (1999, 51), however, is only an illusion. Using Marx's well known phrase, it is confusing 'the thing of logic as the logic of the things' (ibid). There is nothing about regularities which makes anything deterministic. And even highly structured generative rules are still not compelling for specific actions when it comes to their implementation in a pragmatic living world. Yet, sometimes practitioners tend to confuse the mechanical realm as not just the locus of abstract representations but also as their primary plane of action and practical engagement with the world. This is a mistake that owns much to a highly intellectual culture and probably to certain philosophical roots, such as Rationalism. For an artist, as an embodied agent engaged in practice and acts in and on a world there is much room even for actions that have no explanation. To this I would like to add an answer given by Wittgenstein in relation to language and grammar: "to use a word without justification does not mean to use it without right" (Wittgenstein 1968, 289, in Taylor, 1995, 168).

When artists or designers make a decision without a seemingly 'good' reason other than mere causality, that doesn't mean that that choice is not right. Making choices and decisions is simply part of what generative artists and designers do. And there is nothing further on that to be said.
However, that does not mean that nothing further can be said about creativity here.

\section{TOWARDS A PRACTICE OF THE POETIC}

"da red
yell ow
bro won $t$
an orange you
bay jaun
pure people
blew hue
a gree gree in
viol let
pure people
be lack
why it
pee ink"
(Mullen 2002, "Coo/Slur", from Sleeping
with the Dictionary)

The effort made by Wittgenstein as by his followers in extending the philosophical borders of the human agency has similarities to the phenomenology of Martin Heidegger. In his later work Heidegger $(1935,2000)$ observed the origin of creative practice through the ancient Greek concept of 'Poiesis'. In its original meaning Poiesis is a non-separated practice that refers both to thinking and to poetry making, where the creative act can be seen as a unity of the two. Pre Socratic thinkers are exemplars of this unified praxis, and fragments such as 'one cannot step twice into the same river' (Heraclitus, from Plutarch De E apud Delphous 392B, trans. Kahn, 1979, 54) are minimalistic poetic dialects which are at the same time an expression of the depths of Heraclitus' philosophical thought and his engagement with the world through improvised personal experiences.

Algorism stirs these notions through the fuzzy way in which generative systems encourage unique interpretations, free play and improvised confrontations with ever renewed unfolding situations. This can potentially inspire a practice of Poiesis in its original meaning, a creative act intertwining both the depth of the thoughtful and the poetic of experience and improvisation.

Here I would like to return to Ito and Balmond's pavilion. What is especially captivating there is not just the simplicity of the rules that managed to achieve such a rich and complex structure. But that these designers used a simple geometric rule to break down a more inherent rule system: that of the architectural slab with its obvious language of columns and a roof, windows and a door. Balmond's rule that breaks another is not just a mere act of intuition but also an expression of free 
will, for it takes true freedom in order to break a rule that has become inherent within the locus of modern architecture. For phenomenologists, as for Wittgenstein, the ultimate act of creativity is that of true liberation, such as applying rules and at the same time being liberated from them. For this reason, it would be far more inventive, if designers of artificial life models would explore systems that violate evolutionary rules of adaptation, and thus challenge natural ecology metaphors.

'I set myself rules in order to be totally free' is a phrase related to George Perec, the pioneer of the French literary group Oulipo. The group's manifestoes encourage writers to set rules, constrains and procedures by which to accommodate the writing process as a strategy of liberation (as in Harryette Mullen's poem above). These rules are but means to an end, to critically engage with conventionalities and to explore new forms of textuality. They merely mean to set the escape route from the invisible prison of thought.

Interestingly, Bouveresse (1999) discusses the danger as well as potential of being in a jail and having a jailor. An invisible jail without a jailor is yet a far more dangerous prison, as it might be mistaken for a home. Generative art and design as a practice of rules offers the opportunity at least to see the bars.

\section{ACKNOWLEDGEMENT}

I would like to thank my supervisor, Philip Steadam from The Bartlett, UCL, for his insightful discussions that have inspired many of the ideas in this paper.

\section{REFERENCES}

ARUP AGU (2007) The Serpentine Gallery Pavilion - Cecil Balmond with Toyo Ito 2002, Images. Obtained by the courtesy of ARUP AGU.
Bouveresse, J. (1999) Rules, Dispositions, And The Habitus. In Shusterman, R. (Ed.) Bourdieu : A Critical Reader, Oxford ; Malden, Mass., Blackwell Publishers, pp. 45-63.

Cohen, H. (2008) Reconfiguring. In Brown, P., Gere, C., Lambert, N. \& Mason, C. (Eds.) White Heat Cold Logic : British Computer Art 1960-1980, Cambridge, Mass., MIT Press.

Heidegger, M. (2000:1935) Introduction to Metaphysics, trans. by Fried, G. \& Polt, R. New Haven, Yale University Press (Originally published as Einfuehrung in Die Metaphysik).

Ito, T., and Balmond, C. (2002) Serpentine Gallery Pavilion 2002: Toyo Ito with Arup, Tokyo, Japan, a division of Workshop for Architecture and Urbanism, Tokyo, Japan.

Kahn, C. H., (1979) The Art And Thought Of Heraclitus: An Edition of The Fragments With Translation And Commentary, Cambridge University Press, UK.

McCormack, J. (2012) Creative Ecosystems, In McCornack, J. \& D'Inverno, M. (Eds.) Computers And Creativity, 1st ed. New York, Springer, pp.3960.

McCormack, J. (2010) Niche Constructions, http://jonmccormack.info, accessed: 10.01.2014.

Mullen, H. R. (2002) Sleeping with the dictionary, Berkeley, University of California Press.

Nake, F. (2012) Construction And Intuition: Creativity In Early Computer Art. In McCornack, J. \& D'Inverno, M. (Eds.) Computers And Creativity, 1st ed. New York, Springer, 61-94.

Taylor, C, (1995) Philosophical Arguments, Harvard University Press, USA.

Wittgenstein, L. (1968:1953) Philosophical Investigations, trans. by G.E.M., $3^{\text {rd }}$ Edition, Oxfrod: Blackwell, UK. 